Article

\title{
Political Response to Foot-and-Mouth Disease: A Review of Korean News
}

\author{
Chang-Ryong Ko ${ }^{1}$, Sung-Soo Seol ${ }^{1}$ and Geonha Kim ${ }^{2, *}$ \\ 1 Department of Economics, College of Economics and Business Administration, Hannam University, \\ Daejeon 34430, Korea; bluecore@hnu.kr (C.-R.K.); s.s.seol@hnu.kr (S.-S.S.) \\ 2 Department of Civil and Environmental Engineering, College of Engineering, Hannam University, \\ Daejeon 34430, Korea \\ * Correspondence: kimgh@hnu.kr; Tel.: +82-42-629-8361
}

Academic Editor: Marc A. Rosen

Received: 9 November 2016; Accepted: 15 March 2017; Published: 20 March 2017

\begin{abstract}
The 2010/2011 foot-and-mouth disease (FMD) outbreak in Korea produced about 4500 burial sites for 3.5 million animal carcasses, which can be summarized as quick, mass burials, at or near the outbreak farms. An FMD outbreak has occurred nearly every year since the big outbreak, although the sizes of these outbreaks have been small. This article presents the rationale behind government policies for FMD outbreaks and disposal sites, the secrecy of the government administration and the neglect of scientific data. We compared government news announcements with news from the non-governmental sector by analyzing all the news for FMD and disposal sites from 29 October 2010, the first day of the big outbreak to August 2016. We found that the Korean response to the FMD outbreak originated from political purposes. We present four rationales for our arguments including: (1) a military collision between North and South of Korea; (2) the reformation of four big rivers; (3) the incident at the Fukushima Atomic Energy Plant of Japan; and (4) the national elections. We believe that the next response should be based on scientific data and proof, and also from the environmental perspective, not the political or industry perspective.
\end{abstract}

Keywords: foot-and-mouth disease; FMD; disposal site; Korea; political response; news review

\section{Introduction}

Until the year 2000, foot-and-mouth disease (FMD), as a new animal epidemic, had not been experienced in Korea since the 1930s. The outbreak was small, so the government at the time and a few academics were not concerned about FMD. However, the 2010/2011 outbreak battered Korea, raising a national state of emergency and produced approximately 4500 burial sites for the 3.5 million animal carcasses.

The characteristics of the Korean response to FMD for the 2010/2011 outbreak can be summarized as quick, mass burials, at or near the outbreak farms, given the rapid spread of the disease. These mass burials raised many technical issues, such as the massive burial methods used; the usual monitoring of the sites; leachates and contamination; and the no or very slow decomposition of animal carcasses from the burial time [1]. These technical issues raised many social issues such as the safety of the drinking water; agricultural products and food; and animal farmers. Furthermore, these social issues have occurred nearly every year after the mass outbreak, although the sizes have been small. Since the completion of the big outbreak, the government has reported that there are no problems at the disposal sites. However, the non-governmental sector has said that there are still problems to be solved, with Seol et al. [2] suggesting that The Center for Bio-Organic Waste removes the animal carcasses based on the experience of a research base for animal carcasses. 
Furthermore, we examined how the Korean government responded to the FMD outbreaks and what people thought about the outbreaks and the government responses. Lee [3] showed the difference between the government and public discourse on the FMD outbreak from an analytical review of the news. Another author named Lee [4] summarized that the policy was paternalism moved towards populism. In contrast, this article wants to show the rationale of the government policies for the FMD outbreaks through a comparison with the news from the non-governmental sector. The result of this article explains why the author [4] concluded that the Korean FMD policy was characterized as populism. This article is the result of the efforts made to determine the features of the whole FMD response in Korea.

\section{Methods and Data}

\subsection{Overview of the Korean Foot-and-Mouth Disease (FMD) Response}

The small 2000 outbreak of FMD was the first outbreak since the 1930s and was followed by a small outbreak in 2002. The 2010 outbreak, however, was large enough to raise a national state of emergency. The large outbreak in 2010 took place from November 2010 to the end of April 2011. Just after the burial of animal carcasses (Table 1), the no-touch policy for the burial sites was started and lasted for three years. After three years, people could use the land used for the burial sites with the permission of the local government. We refer to the three-year no-touch period as the no-touch phase and the period after this as the re-use phase.

Before and during the outbreak period, there were socio-political events that may have affected the FMD response and include a military collision; the accident at the Fukushima Atomic Energy Plant; and the national elections for the national and local assembly.

Table 1. Short history related to the outbreaks of foot-and-mouth disease (FMD).

\begin{tabular}{cc}
\hline Time & FMD and Socio-Political Issue \\
\hline January 2010 & Small outbreak of FMD (6 cases) \\
April 2010 & Small outbreak of FMD (11 cases) \\
September 2010 & Acquisition of FMD clean country status \\
November 2010 & Big outbreak of FMD (150 cases, burial of 3.5 million animals) \\
& Military collision between North and South Korea \\
December 2010 & Political clash regarding the 2011 National Budget \\
March 2011 & Accident at the Fukushima Atomic Energy Plant \\
April 2011 & Election for the National and Local Assembly/Termination of outbreak \\
November 2013 & End of the no-touch period/Start of the re-use period \\
\hline
\end{tabular}

\subsection{Methods}

First, we examined the news for stories on FMD and disposal sites using our analytical framework. Second, we listed the main responses, happenings, facts or opinions from the results of the analytical framework using a historical perspective.

The analytical framework can be described in three sections. First, we classified the time frames after the big outbreak of 2010/2011 into three phases according to the management of disposal sites: the big outbreak period (29 November 2010 to 30 April 2011); the no-touch period spanning three years (1 May 2011 to 29 November 2013); and the reuse period since 30 November 2013. The no-touch three-year period refers to the three years where the sites were protected under the Animal Epidemic Protection Law. After the three-year period, reuse was determined by each individual local government.

Second, news content was classified into four categories: response; evaluation; recovery; and impact, which is a modification of the traditional classification of disaster phases in disaster management studies. In comparison, the phases of disaster management suggested by the U.S. Federal Emergency Management Agency (FEMA) are mitigation, preparedness, response, and recovery [5]. 
In Australia, mitigation has been replaced by prevention and is called the prevention, preparedness, response, and recovery (PPRR) approach to disasters [6]. In the lead up to the Korean FMD outbreak, there was no prevention phase. In our study, we changed the phases to categories which included the phases and detailed components: response; evaluation; recovery; and impact. Each category had sub-categories seen in Table 2.

Table 2. Categories used in the analytical framework.

\begin{tabular}{lll}
\hline Category & Sub-Category & Contents \\
\hline & 1.1 Measures & Drinking water, sites, information, and general, etc. \\
& 1.2 Rules/Guidelines & Manual, real-name responsibility system, citizen participation. \\
1. Response & 1.3 Organization & National/local control tower, field team, management. \\
& 1.4 Budget & Water system, compensation for animals, general expenses \\
& 1.6 Monnitoring & Disposal method, disinfectants, odor, recycling, IT systems, leachate. \\
\hline \multirow{2}{*}{ 2. Evaluation } & 2.1 Response system & Sites, leachate, contamination. \\
\hline 2.2 Opinion & Measures, guidelines, organization, budget, technology, etc. \\
\hline 4. Recovery & 3.1 Excavation & Excavation, standards for recovery, budget, etc. \\
\hline
\end{tabular}

Third, we divided the perspectives presented by the newspaper articles into government and non-government. Government, in our study, was defined as the National Disaster Center; directly related ministries such as the Ministry of Agriculture and Forestry (hereafter agriculture ministry) and the Ministry of Environment (environment ministry); and experts from directly related government agencies. Non-government included the national or local Assembly; the media (including the opinion of the general populace); the experts (scientists) and non-related ministries and agencies. About a half of non-governmental opinions came from the media, followed by the Assembly. Newspaper articles are simply called news hereafter.

\subsection{Data}

All news from the registered news agencies in Korea were searched using the KINDS DB (Korean Integrated News Database System database) [7], which is the aggregation database of Korean media. We searched the database for the combined keyword of FMD and disposal sites from 29 October 2010 (the first outbreak day) to 31 August 2016. We retrieved 6828 news results, but only selected 3345 news items (as shown in Table 3). The excluded news results were ones not directly related to the environment; multiple reporting from different news agencies; and consequent reporting of the same news. We classified each news item according to our analytical framework.

Table 3. Sources of news articles.

\begin{tabular}{cccccc}
\hline & Local & National & Economic & Total \\
\hline \multicolumn{2}{c}{ Number of media } & 25 & 11 & 5 & 41 \\
\hline \multirow{2}{*}{ News } & Number & 1866 & 986 & 493 & 3345 \\
& $\%$ & 55.8 & 29.5 & 14.7 & 100.0 \\
\hline
\end{tabular}

Local $=$ local media such as newspaper and broadcasting; National = national media; Economic $=$ media reporting specialized in business and economics.

According to our defined phases, the news regarding FMD was heavily concentrated in 2011, the year of the big outbreak, at $88.3 \%$ and has dramatically decreased since then, despite the small annually recurring outbreaks. Therefore, we classified the news into three periods starting from the big outbreak of $2010 / 2011$. The news during the big outbreak period was $66.2 \%, 30.8 \%$ in the no-touch period and $3 \%$ in the reuse period. 
Geographically, news for the FMD disposal sites was from the heavy outbreak areas, despite the declaration of the national state of emergency. News from the four big outbreak provinces such as Kyunggi-do (50.7\% of the disposed animals); two Chungcheong-dos (23.1\%); and Kyungsangbuk-do $(14.0 \%)$, consisted of $48.5 \%$. However, the news from Seoul should also be added to this ratio as the Kyunggi-do province surrounds Seoul, the capital of Korea and provides it with water. This trend was the same for all three periods.

By detailed category in Table 4, the top three content sub-categories were Monitoring with $25.4 \%$; followed by Opinions at 20.6\%; and the Evaluation of government response systems at $12.7 \%$. News on the Excavation issue was only $1.0 \%$.

Table 4. Major news by phases and sub-category (\%).

\begin{tabular}{clcccc}
\hline Phases & Sub-Category & Outbreak & No-Touch & Reuse & Total \\
\hline Response & 1.6 Monitoring & 23.1 & 31.6 & 12.0 & 25.4 \\
Evaluation & 2.2 Opinions & 18.1 & 24.2 & 40.0 & 20.6 \\
Evaluation & 2.1 Response system & 13.9 & 10.4 & 10.0 & 12.7 \\
Response & 1.1 Measures & 14.0 & 9.7 & 4.0 & 12.4 \\
Response & 1.5 Technology & 9.7 & 5.8 & 6.0 & 8.4 \\
Impact & 4.1 Unrest/Damage & 8.3 & 6.1 & 3.0 & 7.4 \\
Response & 1.2 Rules/Guidelines & 5.7 & 2.0 & 9.0 & 4.7 \\
Response & 1.3 Organization & 3.8 & 1.7 & 0.0 & 3.1 \\
Response & 1.4 Budget & 3.4 & 6.3 & 3.0 & 4.3 \\
Recovery & 3.1 Excavation & 0.0 & 2.1 & 13.0 & 1.0 \\
\hline \multirow{2}{*}{ Total } & \% & 100.0 & 100.0 & 100.0 & 100.0 .0 \\
& Number of news & 2214 & 1031 & 100 & 3345 \\
\hline
\end{tabular}

By news source, $62.2 \%$ was from government and $37.8 \%$ from non-government sources. The ratio by phase was similar to this total ratio (Table 5).

Table 5. Category by subject and perspectives (\%).

\begin{tabular}{lccc}
\hline Category & Government & Non-Government & Total \\
\hline 1.Response & 76.0 & 24.0 & $100(1947)$ \\
2.Evaluation & 51.3 & 48.7 & $100(1114)$ \\
4.Impact & 2.4 & 97.6 & $100(249)$ \\
3.Recovery & 71.4 & 28.6 & $100(35)$ \\
\hline Total & $62.2(2081)$ & $37.8(1264)$ & $100(3345)$ \\
\hline \multicolumn{4}{c}{ Note: () represents the number of news. }
\end{tabular}

By category, as shown in Table 5, news in the Response category was at the top with approximately $60 \%$ and those of Evaluation at 33\%. Most Response and Recovery news were from the government side, whereas most Impact news was from the non-governmental side. Evaluation news came from both sides.

\section{Results}

\subsection{Bias of News}

One important point in news analysis, especially for environmental issues, was the bias of the news and media where some media and news were extremely positive, while others were extremely negative. We also checked all the news in the Opinion sub-category in the Evaluation category, as shown in Table 6.

Out of 689 Opinions, the government opinions were $41.4 \%$; $58.6 \%$ were non-government opinions; $11.8 \%$ were neutral. The news in government opinion could also be classified into positive and 
negative responses such as "safe or no-problem"; "need a make-up" of disposal sites; and "problem". The "make-up" means the fix of disposal sites to make public perceive that disposal sites are safe. News from non-governmental opinions was "possible contamination" at $20.0 \%$ and "contamination" at $26.9 \%$. There was no big sign of biases in the statistical result. In addition to these statistics, we tried to find negative news. We did not further pursue this trial as we needed another study on the standards of judgment for negative and positive.

Table 6. Distribution of opinions in the news.

\begin{tabular}{|c|c|c|c|c|c|}
\hline \multicolumn{2}{|c|}{ Opinion } & \multirow{2}{*}{$\begin{array}{c}\text { Outbreak } \\
11.5\end{array}$} & \multirow{2}{*}{$\begin{array}{c}\text { No-Touch } \\
23.7\end{array}$} & \multirow{2}{*}{$\begin{array}{c}\text { Reuse } \\
10.0\end{array}$} & \multirow{2}{*}{$\begin{array}{c}\text { Total } \\
15.8\end{array}$} \\
\hline \multirow{4}{*}{ Gov't } & Safe & & & & \\
\hline & Make-up & 27.5 & 12.0 & 5.0 & 20.6 \\
\hline & Problem & 3.3 & 8.4 & 0.0 & 4.9 \\
\hline & Sub-total & 42.3 & 44.2 & 15.0 & 41.4 \\
\hline Neutral & Disputable & 6.5 & 22.1 & 0.0 & 11.8 \\
\hline \multirow{3}{*}{ Non-Gov't } & $\begin{array}{c}\text { Possible } \\
\text { contamination }\end{array}$ & 22.3 & 13.7 & 37.5 & 20.0 \\
\hline & Contamination & 29.0 & 20.1 & 47.5 & 26.9 \\
\hline & Sub-total & 51.3 & 33.7 & 85.0 & 58.6 \\
\hline \multirow{2}{*}{ Total } & $\%$ & 100.0 & 100.0 & 100.0 & 100.0 \\
\hline & Number & 400 & 249 & 40 & 689 \\
\hline
\end{tabular}

\subsection{The Big Outbreak Phase}

The most noticeable news during the big outbreak phase was mostly from the disposal sites: the safety of drinking water and food; the poor workability of the standard operating procedure (SOP); the arbitrary process of killing and burial; and the difficulties of the field workers. The second biggest news was from the government response and included leadership and secrecy about disposal sites and contamination.

Regarding the public concern in these fields, the government solved the drinking water issue with systemized water services to all the concerned regions and cost about $\$ 4.5$ billion USD. In addition, the government provided about $\$ 1.7$ billion USD to the animal farmers for the costs of animal disposal [8].

The leadership issue was due to the fact that the big outbreak was the first time it had been experienced. The Guidelines for Urgent Action for FMD published by the agriculture ministry classified the FMD outbreak into four levels by size. At all levels except the worst, the agriculture ministry was to be in charge of the outbreak. The worst phase was defined as an outbreak in more than three provinces and was to be controlled by the National Disaster and Safety Center under the Prime Minister during a national state of emergency. This center is normally run by the Ministry of Administration and Safety and is in charge of the missions related to local governments. At the very earliest time of the outbreak, the agriculture ministry had been in charge of the Central FMD Response Center under the Presidential Office. However, when the outbreak reached the worst level, the National Disaster and Safety Center became involved in the outbreak. These two headquarters are perceived to have mismanaged the action on behalf of the central government. Furthermore, there had been no specific definition in the laws and regulations that stated that animal epidemic was a category of the national disaster at the time of the 2010/2011 outbreak [8-10].

The news reported other mishandling in the FMD response during the first few months. First, the agriculture ministry insisted on mass disposals in the FMD-free states, whereas The National Disaster and Safety Center, insisted on vaccination as the appropriate response. Second, there had been different opinions and responses even at local government level between the departments of agriculture, and water and environment. The agricultural department thought burial was sufficient, 
despite the concerns that the water and environment department had regarding the aftermath of the disposal sites [1].

Regarding the measures for the outbreak field, even the SOP for FMD created mismanagement for field workers. There were two SOPs published by the agricultural ministry and the environment ministry. The SOP of the agricultural ministry focused on the quick treatment of carcasses, whereas the environment ministry focused on the management of the environment post-burial. Furthermore, the SOPs were not appropriate for mass burial, as Korea had no previous experience of big outbreaks. Therefore, the suggestions or best practices from the FMD field became the foundations of the SOP without any scientific checking or testing. In addition, untested measures or techniques suggested by high-level officers created big disputes and were finally canceled included real-time remote sensors for monitoring disposal sites [11]; the composting of leachates from disposal sites [12]; and burning leachate after mixing with sawdust [13].

Another mishandled issue was due to the lack of resources including workforce; quicklime; and disinfectants, along with insufficient disposal sites along with the existing SOP manual [14-16]. The lack of quicklime and disinfectants created many problems at the disposal sites having problems and quickly made the news [17].

\subsection{The No-Touch Phase}

The No-Touch period of the disposal sites began from the start time of each burial. Therefore, the response to the outbreak and the disposal sites occurred almost simultaneously during the outbreak period. The agricultural ministry had responsibilities until burial, which was when the environment ministry took over; however, the local government had responsibilities in field management.

The characteristics of the social climate during the No-Touch phase are as follows: first, the environmental awakening of people had already increased sharply due to the FMD and the incident at the Fukushima Atomic Energy Plant in Japan. Second, as news about the response decreased, news regarding the evaluation increased from both government and non-governmental sources as shown in Figure 1. This means that many non-governmental organizations (NGOs) and news sources pointed out the potential contamination issues, which the government either denied or ignored the evaluation from non-government sources.

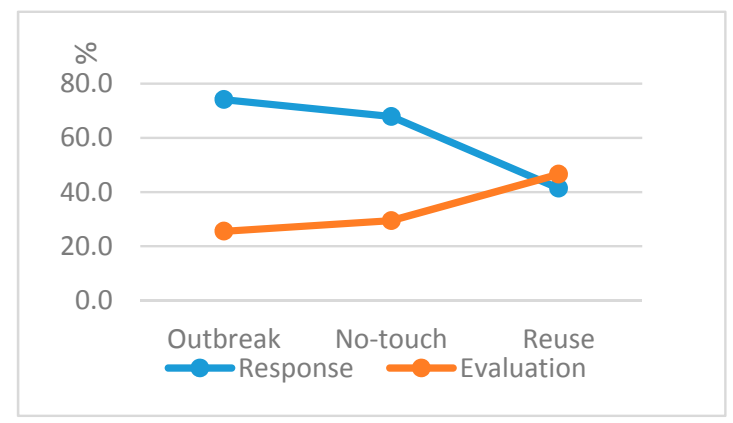

(a)

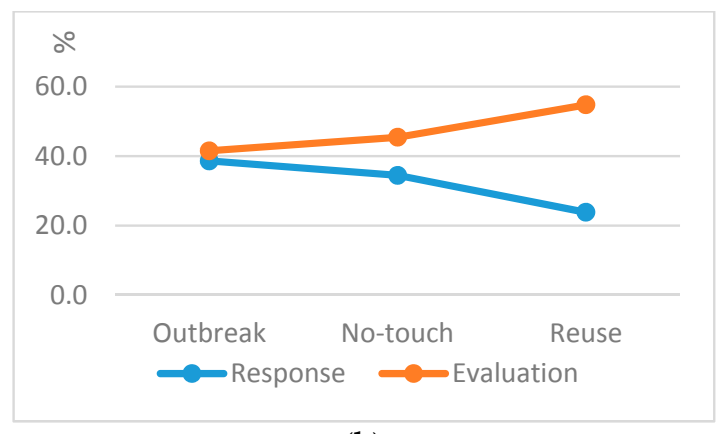

(b)

Figure 1. The trend of the main category by phase. (a) Government; (b) Non-government.

It is surprising that many news sources reported that government across all levels hid information regarding the disposal sites: Yeoju City [18] at the city level, Choongcheongbuk-do $[19,20]$ at the province level, all local government [21], and environment ministry [22-25] at the national level.

About $70 \%$ of local government actions during the period were the response to disposal sites, such as the budget, workforce, technology or continuous monitoring. 


\subsection{The Reuse Phase}

During the Reuse phase, news regarding disposal sites had been decreasing sharply. This may be because people are less interested in the issue as time passed. The top news from non-government sources was the evaluation of disposal sites, followed by measures and recovery. The important fact to note was that the news on evaluation have accumulated year after year, and are mostly negative about the leachates; the impacts of the leachates; and the lack of warnings regarding the danger of excavation or reuse of the disposal sites.

Information from the annual reports of the Safe-Enhancement, Action-Oriented, FlexibleManagement, Eco-Friendly Technology (SAFE) Research Team [26] concerning the disposal sites, reported that a member of the National Assembly released some facts surrounding the location of the sites placed in non-acceptable areas and that there were no signs of animal decomposition.

Regarding agricultural products, the National Agricultural Products Quality Management Service announced that they had detected the disease in agricultural products near the disposal sites; however, the ratio detected was $5 \%$ out of 100 samples [27]. In particular, news of contamination in a pig breeding region was shocking and obtained through the survey results of a local government research institute. Approximately $40 \%$ of pig disposal sites are located near a residential area, and $70 \%$ of disposal sites are exposed to contamination $[24,28]$. News from the local Assembly reflects these types of warnings from experts. In some cases, the local Assembly pointed out that farmers had excavated disposal sites without prior reports or approval of local government [29]. From the early period of the landfill, there has been similar news [30] and comments from Assemblymen who called for reactions of the local government.

There were two central government policies reported in the reuse phase: the first was the report of the Board of Audit and Inspection of Korea [31] for the measures of animal disposal sites of the ministries [32]; and the second was the announcement of the Ministry of Agriculture and Forestry for the reuse of animal carcasses from FMD and AI (Aviation Influenza) to animal feeds and fertilizer [33]. The report was a national review of policies for disposal sites and revealed the statistics of the reuse of disposal sites in a province: reuse $57.1 \%$, construction $3.7 \%$, vacancy $38.0 \%$, and the extension of the no-touch phase $1.1 \%$, out of a total number of 2247 disposal sites. Furthermore, the report stated that there were leachates detected at some disposal sites, and that vacant sites after transfer were still contaminated after two years of transfer. In addition, the report pointed out some technological and managerial problems and recommendations for the relevant ministries to adjust the usage of microbiological measures during landfill; the diagnosis of contamination; the disinfection or transfer of contaminated sites; the monitoring of all the sites; the guidelines for special monitoring of contaminated sites; the excavation procedure after three years; and the selection of new disposal sites according to the new SOP. Most recommendations related to the response and measures of the agriculture ministry.

Local government actions during the reuse phase were very diverse due to their role and responsibilities for disposal sites. The issues surrounding the measures undertaken were technology, budget, the monitoring of disposal sites; and rules and guidelines. The recovery news focused on the excavation of the disposal sites; the management guidelines; and the budget. The evaluation news concerned safety; contamination; supplement; and new measures. News from experts surrounded the diagnoses of leachates at the disposal sites.

\section{Discussion}

\subsection{News for Technology}

There was a difference in the recovery news by region, according to their main animals. The province of Kyungsangbuk-do, specialized in cow breeding where the carcasses easily decomposed, conducted seminars on the administration of the disposal sites and reached a decision on the early stabilization of disposal sites [34]. In contrast, the pig regions were worried about the excavation of disposal sites and stabilization post-excavation as the sites showed no signs of decomposition [35,36]. 
As for technologies, disinfectants, effective micro-organisms, and disposal methods were the frequent news items during the big outbreak period. Many news sources reported the overuse of strong disinfectants in many areas, for example, three times stronger than recommended $[37,38]$.

During the No-Touch period, the news reported on the geographical information systems (GIS) used for the location of disposal sites [11] and the real-time underwater monitoring systems [39] technologies. Furthermore, the agriculture and environmental ministries started R\&D programs to create technology for site management. The agriculture ministry commissioned small research projects [40], whereas the environment ministry launched a comprehensive five-year SAFE research project led by Hannam University [41]. This research team developed comprehensive methods for excavation, complete decomposition, and the recovery of the disposal sites.

\subsection{Secrecy in Dealing with Disposal Sites}

In this review, we saw a trend regarding the secrecy or intentional neglect of the facts was due to the following: First, the National Disaster and Safety Center ordered that disposal sites were the responsibility of Vice Chancellor of each local government [42] and that the safety of each disposal site should be under an individual civil servant [43]. This order went down to local government levels through the Vice Chancellor of the local government as the central government designated each Vice Chancellor. Furthermore, our President visited the center and ordered that all the problems at the disposal sites would be resolved within the next month under the responsibility of each minister [44]. As the nationwide elections for the National Assembly or local governments were to be held in Korea in April, under this order, a local government would have ordered that every civil servant controls the safety of each disposal site under their name and their desk. Furthermore, the head of local government would have obtained the written oath from each civil servant that there were no problems at their respective sites. This procedure may have caused many civil servants to keep any issues regarding their responsible site secret [45-47].

Second, the regulations surrounding leachate monitoring under the Animal Epidemic Law had been weakened by the end of 2010, the first year of the big outbreak, which led to a further weakening of the leachate contamination diagnoses. Furthermore, the environment ministry reduced the standards of contamination [48], which meant little observation for leachate and contamination problems [49].

Third, many news sources reported that the environment ministry, which had authority for the disposal sites, had hidden away any bad news [13,50]. The Board of Audit and Inspection of Korea revealed that the environment ministry even misclassified many potentially contaminated sites as good, when conducting a province-wide survey of disposal sites [51]. The province Kyungsangbuk-did publicly announce, that there was "no problem in disposal site" [52] and that they had broken up the team managing the disposal sites [53].

It is noteworthy that the Microbiological Society of Korea announced the results of their third-year investigation at the disposal sites, which were different from the opinions of prior years. Their announcement was that that they had detected the virus underwater near disposal sites and confirmed the flow of leachate. In addition, they warned of a second contamination [54].

What is the purpose of this secrecy? Disasters can occur at any time, so a systemic approach based on science and technology and leadership from a central government plays a crucial role in disaster management plans: Hamilton [55] introduced the United Nations (UN) experts recommendation for disaster reduction by science and technology; and Moynihan [56] pointed out the importance of the role of the central government.

\section{Conclusions}

There is a clear difference between government discourse and non-government discourse. During the big outbreak phase, many government policies were not suitable for application in the outbreak fields. Therefore, the opinions of many in the non-governmental sector were worried about drinking water and possible contamination; the mishandling of each policy; requesting clear information; 
and policy suggestions. After the outbreak phase, the government insisted that there were no big problems, only minor issues to fix at the disposal sites. In contrast, the non-governmental sector pointed out contamination from or at the disposal sites. Although there are decreasing numbers of opinions on contamination, the discourse between the two parties still differs. Lee [3] pointed out that the difference came from the perspective of industry and environment, where the government has focused on the industry perspective, and the non-governmental sector has supported the environment perspective. This interpretation was based on the government cash supports for animal farmers and industry.

We do not agree with Lee [3] because we believe that the difference comes from the perspective of politics and science. The government's decisions and responses to the FMD outbreak were based on a political purpose. During the big outbreak period, there was a military collision between North and South Korea at an island at the end of the northwest, Younpyeong-do on November 2010. Second, there was a political clash on the issue of the reformation of four big rivers during December in the 2011 national budget in the National Assembly. The 2011 budget for this river was approximately $\$ 9$ billion USD and raised severe nationwide environmental disputes. Third, the incident at the Fukushima Atomic Energy Plant in March 2011 also raised further environmental concerns. Fourth, the national election for members of the National Assembly and local Assembly, and the Chancellor of local government was scheduled during April 2011. Therefore, our President ordered the FMD issue to be concluded by the end of March 2011, during the visit to the National Disaster Center. Due to these facts, Lee [4] says Korean FMD policies had moved from paternalism to populism. Under this order, local governments ordered that every civil servant should be responsible for controlling the safety of each disposal site under their individual names. Simply, the order allowed the government to maintain silence on any bad news regarding the disposal sites even though there has been scientific evidence of contamination. Some scientific data has since been released to the news after the change in government.

This is a review of all the news regarding the FMD outbreak and disposal sites. Facts or scientific data were rarely included in media reports or news; therefore, they could not be reported in this article. We expect further study with scientific data will help address actual issues about the disposal sites and the response to the FMD outbreak in Korea. Based on media and news reports, we would suggest that scientific approaches to developing government policy are not being used. We also believe it is difficult for the government to satisfy public concerns, since the issues have accumulated for more than a decade over several government administrations. Additionally, management and media communications were conducted at different levels from local, to ministry, to national. We expect that all the contamination points and the disposal sites should be removed as suggested by Seol and Kim [2]. Furthermore, the next response should be based on scientific data and evidence, and considered from an environmental perspective.

Acknowledgments: This research was funded by the GAIA project, the Korean Ministry of Environment. We thank the anonymous referees for their valuable comments.

Author Contributions: Chang-Ryong Ko searched the data and analyzed it with Sung-Soo Seol. Geonha Kim checked and reviewed the technical content and field stories.

Conflicts of Interest: The authors declare no conflict of interest. The founding sponsors had no role in the design of the study; in the collection, analyses, or interpretation of data; in the writing of the manuscript, and in the decision to publish the results.

\section{References}

1. Ko, C.R.; Seol, S.S. Technology and Policy Measures for Landfill Sites of Foot-and-Mouth Disease in Korea. J. Korea Technol. Innov. Soc. 2013, 16, 978-1005. (In Korean)

2. Seol, S.S.; Kim, G.H. Proposal for a New Form of Environmental Infrastructure to Improve Agricultural Environment-Carcass Recycle Center. J. Environ. Pol. Admin. 2016, forthcoming. (In Korean) 
3. Lee, S.C. The Challenges of Korean Livestock Policy, Grasped by Foot-and-mouth Disease Discourses. Crisisonomy 2012, 8, 90-107. (In Korean)

4. Lee, H.Y. A Policy paradox from paternalism to populism: The case of foot-and-mouth disease in South Korea. Int. Rev. Public Adm. 2013, 18, 233-256. (In Korean)

5. Federal Emergency Management Agency. Comprehensive Emergency Management Framework; Federal Emergency Management Agency: Washington, DC, USA, 1998.

6. Crondstedt, M. Prevention, Preparedness, Response, Recovery-An outdated concept? Aust. J. Emerg. Manag. 2002, 17, 11-13.

7. BIG KINDS. Available online: http:/ / www.bigkinds.or.kr (accessed on 19 March 2017).

8. FMD Central Disaster \& Safety Center. White Paper for FMD Central Disaster E Safety Center; Ministry of Administration and Safety: Seoul, Korea, 2011. (In Korean)

9. Kim, M.K. A Study on Meta-Governance of National Crisis Management System: The Case of Foot-and-Mouth Disease in South Korea. Crisisonomy 2012, 8, 53-82.

10. Yang, G.G. The Role Restructuring of Central Disaster and Safety Countermeasures Headquarters for Integrated Disaster Countermeasures-Focusing on the Foot and Mouth Disease. Crisisonomy 2012, 8, 72-89.

11. FMD disposal site leachate-24-hours monitoring. Financial News, 15 February 2011. (In Korean)

12. Criticism for composting of leachates from disposal sites. Hankyoreh, 17 February 2011. (In Korean)

13. The argument for burning leachate after mixing with sawdust. Hankookilbo, 20 February 2011. (In Korean)

14. FMD, lack of the disposal site and disinfection workforce. Hankyoreh Daily, 5 January 2011. (In Korean)

15. Disposal guideline of FMD unsuitable for environmental preservation. Naeil Daily, 10 January 2011. (In Korean)

16. FMD outbreak until south Kyunggi-do ... Local governments are a war to secure quicklime. Kyunggiilbo, 27 December 2010. (In Korean)

17. Park, D.K.; Yang, G.G.; Riu, S. The Strengthening Efficiency Measures for Disaster Management System in Local Government. Korean Local Gov. Stud. 2012, 13, 131-154.

18. Yeoju, disposal site contamination, 'hide'. Kyunggiilbo, 3 April 2011. (In Korean)

19. Chungcheongbuk-do closes the mouth for monitoring results of the disposal sites. Joongbu Daily, 23 February 2011. (In Korean)

20. "No-problem" disposal sites have leachate, field survey to Jincheon, Choongchungbuk-do. Naeil Daily, 9 June 2011. (In Korean)

21. The local government refused to disclose leachate information. Kookminilbo, 5 July 2011. (In Korean)

22. Strange leachate evaluated by the Ministry of Environment. Hankook Economic Daily, 30 March 2011. (In Korean)

23. 25 percent of FMD disposal sites have leachate, but the government hides. Hankookilbo, 20 December 2011. (In Korean)

24. About $40 \%$ FMD pigs buried near the residential area-Choongchungnam-do Provincial Research Institute. Joongdoilbo, 8 August 2016. (In Korean)

25. They say "no problem" but. Seoul Economic Daily, 20 February 2013. (In Korean)

26. Food safety threatens by antibiotic and disinfectants from the disposal site. Kyunggiilbo, 21 October 2014. (In Korean)

27. Some agricultural products detected food poisoning bacteria. DongAilbo, 16 March 2016. (In Korean)

28. 70\% of FMD disposal sites exposed to contamination. Choongcheong Today, 9 August 2016. (In Korean)

29. Excavation of FMD disposal sites without approval. Choongcheong Today, 11 September 2015. (In Korean)

30. A citizen reported damage of FMD disposal site near a pig farm. Kyungnam-news, 23 November 2012. (In Korean)

31. Board of Audit and Inspection of Korea. Report for the Inspection of Contamination Control Measures for Animal Disposal Sites; Board of Audit and Inspection of Korea: Seoul, Korea, 2015. (In Korean)

32. Board of Audit and Inspection of Korea. Administration of disposal sites inappropriate. Joongangilbo, 24 June 2015. (In Korean)

33. The reuse of animal carcasses from FMD and AI to animal feeds and fertilizer. Joongangilbo, 4 October 2015. (In Korean)

34. Control of FMD disposal sites strengthened by local government. Youngnamilbo, 7 November 2013. (In Korean) 
35. Pig FMD disposal sites are not stabilized even after five years. Financial News, 25 May 2016. (In Korean)

36. Three-year-ago nightmare of FMD may occur again. Segyeilbo, 1 November 2013. (In Korean)

37. Some local government in Kyungki-do were the use of disinfectants by three times stronger than recommended. Hankyoreh Daily, 3 March 2011. (In Korean)

38. Robinson, L.; Knight-Jones, T.J.D.; Charleston, B.; Rodriguez, L.L.; Gay, C.G.; Sumption, K.J.; Vosloo, W. Global Foot-and-Mouth Disease Research Update and Gap Analysis: 5-Biotherapeutics and Disinfectants. Transbound. Emerg. Dis. 2016, 63, 49-55. [CrossRef] [PubMed]

39. Selected 10 best environmental technologies including Real-time Groundwater Monitoring. Herald Economic Daily, 29 May 2012. (In Korean)

40. Agriculture ministry, 31 items selected for R\&D support project. Herald Economic Daily, 22 December 2011. (In Korean)

41. Hannam University, participated in 'GAIA Project'. Joongdoilbo, 17 April 2012. (In Korean)

42. Vice Chancellor in charge of FMD disposal sites. Maeil Economic Daily, 11 February 2011. (In Korean)

43. FMD disposal site, control under each civil servant's name. Chosunilbo, 13 February 2011. (In Korean)

44. Mr. President, problems from disposal sites can be solved by our capabilities. Chosunilbo, 18 February 2011. (In Korean)

45. The first identified groundwater contamination in Icheon where the Ministry of Environment said "No problem". Chosunilbo, 29 March 2011. (In Korean)

46. FMD burial site leachate "leaked" ... "No". Joongbu Daily, 3 June 2011. (In Korean)

47. Yeoju, Hide groundwater contamination from the disposal sites. Kyunggiilbo, 8 April 2011. (In Korean)

48. Ministry of Environment changed the standards of contamination in two months. Hankook Economic Daily, 2 June 2011. (In Korean)

49. Enforcement Rules of Animal Epidemic Protection Law revised towards reducing monitoring network for groundwater. Daeguilbo, 2 March 2011. (In Korean)

50. Ministry of Environment concealed FMD leachate. Mail Economic Daily, 8 October 2011. (In Korean)

51. Administration of disposal sites inappropriate ... environmental concerns. Segyeilbo. Board of Audit and Inspection of Korea, 24 June 2015. (In Korean)

52. Kyungsnagbuk-do, the disposal site management was "no problem". Herald Economic Daily, 6 November 2013. (In Korean)

53. The recovery of FMD disposal sites in Andong. Daeguilbo, 28 November 2014. (In Korean)

54. Pathogenic contamination confirmed from groundwater nearby FMD disposal sites. Chosunilbo, 1 October 2014. (In Korean)

55. Hamilton, R.M. Science and technology for Natural Disaster Reduction. Nat. Hazards Rev. 2000, 1, 56-60. [CrossRef]

56. Moynihan, D. A central agency is crucial for disaster response. Nature 2013, 494, 7. [CrossRef] [PubMed] 